\title{
Vitamin D Supplementation for the Treatment of Depression in Females in a Private Practice Clinic
}

\author{
Vorvolakos $\mathbf{T}^{1,2 *}$ and Athanasiou $\mathbf{M}^{1}$ \\ ${ }^{1}$ Psychiatric Common Primary Care-Private Practice, Alexandroupolis Greece \\ ${ }^{2}$ Associate Professor of Psychiatry and Old Age Psychiatry, Democritus University of Thrace, Greece
}

*Corresponding author: Vorvolakos T, Psychiatric Common Primary Care-Private Practice, Alexandroupolis Greece; Associate

Professor of Psychiatry and Old Age Psychiatry, Democritus University of Thrace, Greece

\section{ARTICLE INFO}

Received: 蔧 October 11, 2021

Published: 慧 October 21, 2021

Citation: Vorvolakos T, Athanasiou M. Vitamin D Supplementation for the Treatment of Depression in Females in a Private Practice Clinic. Biomed J Sci \& Tech Res 39(3)-2021. BJSTR. MS.ID.006313.

\begin{abstract}
During the last decade there is a strong interest regarding the effect that vitamin D plasma levels can have in depression. There are also studies that suggest the use of vitamin D supplementation either by mouth or through light therapy as an add on therapy for depression. Influenced by this evidence, during the winter season of 2019, we used Vitamin $\mathrm{D}_{3}$ supplementation mainly as an add-on therapy for the treatment of patients suffering from depression in our private practice. A small sample of eight patients was treated. All of them were women-Caucasian with Vitamin D insufficiency. An oral dose ranging between 2000 and 4000 UI of Vitamin $D_{3}$ per day was administered. One of them was treated with Vitamin $\mathrm{D}_{3}$ as monotherapy while in the rest, Vitamin $\mathrm{D}_{3}$ was used as an add-on therapy. Vitamin 25(OH) D levels were measured regularly. A significant improvement in depressive symptoms, that was correlated time wise at least with the increased of Vitamin D blood levels, was observed. This is in accordance with patients' satisfaction, which do not consider Vitamin D as another 'Psychiatric drug'. Although results are quite preliminary, there is a strong feeling, that Vitamin D supplementation is effective in treating certain depressive symptoms. Of course, much further study is needed for any firm conclusions.
\end{abstract}

\section{Introduction}

During the last decade there is a strong interest regarding the effect that vitamin D plasma levels can have in depression [1]. There are also studies that suggest the use of vitamin D supplementation either by mouth or through light therapy as an add-on therapy for depression [2]. Influenced by this evidence, during the winter season of 2019, we used Vitamin $\mathrm{D}_{3}$ supplementation mainly as an add-on therapy for the treatment of patients suffering from depression in our private practice. In order to better assess the results of this intervention and also to communicate our experience to other practitioners, we concluded a small case series study with all our depressed patients that received vitamin d supplementation, during a certain time frame.

\section{Material and Methods}

\section{Subjects}

During autom of 2018 and witner 2018-2019 Every patient that was treated for depression that was presented with residual depressive symptoms was assessed for Vitamin 25(OH) blood levels. Subjects with Vitamin D blood levels below 30ngr/ml where assessed for this study. In total ten patients were assessed. Out of them eight where included in the study since two of the patients were suffering from psychosis and not depression and were excluded. All patients were Caucasian women with a mean age of 54,29 (S.D 16,75). (Table 1) 
Table 1: Various numerical parameters of the study, initial with final vitamin d levels were compared with paired T test and had a statistically significant difference with $p=0,014$.

\begin{tabular}{|c|c|c|}
\hline Patiens $(\mathbf{n}=\mathbf{8})$ & Mean & Standard Deviation \\
\hline Age & 54,29 & 16,75 \\
\hline Initial Vitamin D levels & $12,04 \mathrm{ngr} / \mathrm{ml}$ & 7,995 \\
\hline Final Vitamin D levels & $25,65 \mathrm{ngr} / \mathrm{ml}$ & 11,559 \\
\hline $\begin{array}{c}\text { Mean time between } \\
\text { assesments }\end{array}$ & 52,67 & 30,651 \\
\hline $\begin{array}{c}\text { Vitamin D3 } \\
\text { Supplementation Dose }\end{array}$ & 4142,88 & 1399,75 \\
\hline
\end{tabular}

\section{Method}

All subjects were prescribed with Vitamin $\mathrm{D}_{3}$ oral supplementation oral dose ranging between 2000 and 5000 UI of Vitamin $\mathrm{D}_{3}$ per day was administered. One of them was treated with Vitamin $\mathrm{D}_{3}$ as monotherapy while in the rest; Vitamin $\mathrm{D}_{3}$ was used as an add-on therapy. Levels of Vitamin 25(OH) were assessed again within two months' time frame. Patients with major changes in their treatment such as addition of another antidepressant were to be excluded from this study but in our sample nothing like this occurred during the time frame of this study. Qualitive analysis was used on the psychiatric records that were kept in our private practice in order to assess the symptoms that are more likely correlated with low vitamin D levels. Qualitive analysis was also used in the follow up assessment of the patient in order to detect the symptoms that might have responded to vitamin D supplementation. Final assessment took place three months after the first assessment for each individual. Paired T test was used to compare changes in Vitamin 25(OH) blood levels. SPSS for windows in version 15.0 was used for this comparison.

\section{Results}

All assessed patients had some type of Vitamin D deficiency mean level of Vitamin $\mathrm{D}(\mathrm{OH})$ was $12,04 \mathrm{ngr} / \mathrm{ml}($ S.D. 7,995) with levels ranging from $4,5 \mathrm{ngr} / \mathrm{ml}$ to $26,5 \mathrm{ngr} / \mathrm{ml}$. Seven out of eight having vitamin d blood levels below $20 \mathrm{ngr} / \mathrm{ml}$. The mean dose of Vitamin $\mathrm{D}(\mathrm{OH})$ supplementation was 4142,88 units/per day (S.D $1399,75)$, with most of them taking a dose of 4000 units/per day. Final assessment of Vitamin D (OH) levels took place within two months period, mean time of 52,67 days (S.D. 30,651 ) while it was still in winter. There was a significant increase of Vitamin D (OH) blood levels 25,65ngr/ml (S.D. 11,559) p=, 014 (Table 1). Qualitive analysis showed that the main complain that all patients had in common was psychomotor retardation less common but significant was also morning depression. These symptoms and especially psychomotor retardation tend to improve in various degrees two months or more after the beginning of Vitamin D supplementation (Figure 1).

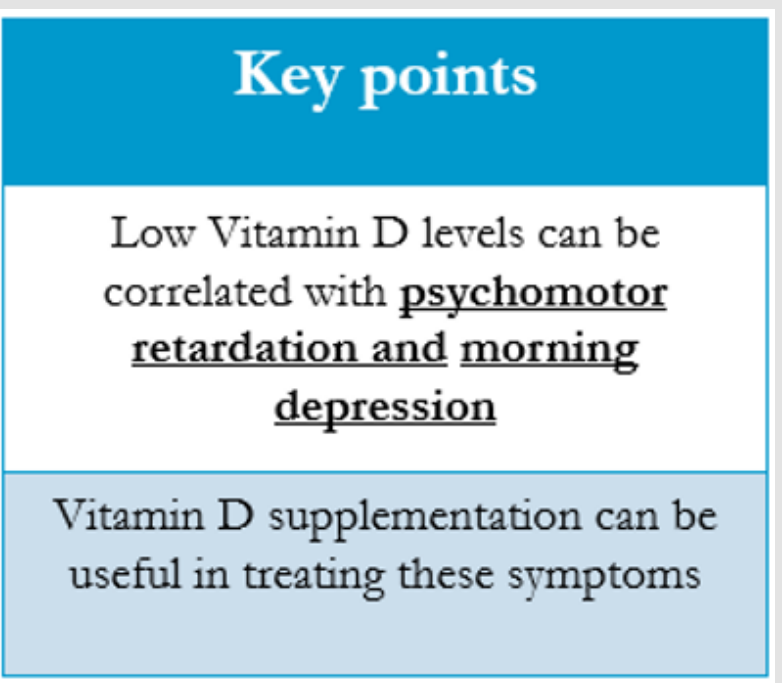

Figure 1:

\section{Discussion}

This is a prospective case series; its results are hopeful. It seems that there is a strong possibility that depressed female patients with a certain residual symptom profile might also suffer from vitamin d deficiency. More specifically symptoms such as psychomotor retardation or morning depression seem to be more correlated with vitamin d deficiency [3]. This study was conducted in total in winter time. This happened since we wanted to reduce confounders such as sun exposure, which is much more likely to happen during summer, and can change the levels of vitamin $d$ in blood regardless of our supplementation [4]. It is important to understand though that in this case psychiatrists should change their treatment culture. While in almost all their care tend to treat almost completely without biological markers, vitamin $\mathrm{d}$ supplementation for treatment of depression requires a different approach. In our study first we check and if there was a vitamin $\mathrm{d}$ deficiency and then we prescribed supplementation of vitamin D [5]. Vitamin $D_{3}$ was prescribed since it seems to be a better alternative in comparison with other vitamin D supplements such as Vitamin $\mathrm{D}_{2}$ [6].

A significant improvement in depressive symptoms, that was correlated time wise at least with the increased of Vitamin D blood levels, was observed. This is in accordance with patient's satisfactions, which do not consider Vitamin D as another 'Psychiatric drug'. Caution should be placed thought to the regular follow up of Vitamin D levels since high above normal Vitamin D levels can also be toxic [7]. So if Vitamin D levels are raised above limits Vitamin D supplementation should be stopped. Furthermore, during summer period Vitamin D levels are raised since our body composes it to higher degree due to increased sun light 
exposure, thus vitamin D levels must be more thoroughly checked during summer time. This brings us to another point. The aim of supplementation is the increase of vitamin D levels in the body. If we can achieve that with other means except prescribing a supplement such as sun exposure it is also good practice to try. The knowledge of the effect that vitamin $d$ can have in the mood and the benefits of sun exposure related to it, might motivate a significant proportion of depressed patients to increase their outdoors activities [8].

This study has significant limitations. Firstly, it is a small study. There are very few patients included. The researchers present this as a case series and not a cohort or other more powerful type of study. Furthermore, the fact that all patient were Caucasian women increases somehow the power of this study. The other limitation is the fact that no standardized assessment of patients initial status or treatment progress, with the use of questionnaires occurred. This makes more difficult to interpret study's findings. To our view since the aim of our approach was to treat residuals symptoms it was difficult for these symptoms to be detected through formal questionnaires that asses overall depression, furthermore the observation and consensus of two specialized psychiatrists has its value when we asses depression and gives some addition credibility to the results. Also, qualitive analysis that we used is an acceptable measure of outcome [9].

\section{Conclusion}

Although results are quite preliminary, there is a strong feeling, that Vitamin D supplementation is effective in treating certain depressive symptoms. Of course, much further study is needed for any firm conclusions.

\section{ISSN: 2574-1241}

DOI: 10.26717/BJSTR.2021.39.006313

Vorvolakos T. Biomed J Sci \& Tech Res

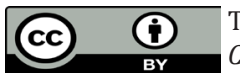

This work is licensed under Creative Commons Attribution 4.0 License

Submission Link: https://biomedres.us/submit-manuscript.php

\section{Competing Interests}

The authors declare that they have no competing interests.

\section{References}

1. Holick MF (2017) The Vitamin D Deficiency Pandemic: Approaches for Diagnosis, Treatment and Prevention. Reviews in Endocrine and Metabolic Disorders 18(2): 153-165.

2. Holick MF, Binkley NC, Bischoff Ferrari HA, Gordon CM, Hanley DA, et al. (2011) Evaluation, Treatment, and Prevention of Vitamin D Deficiency: an Endocrine Society Clinical Practice Guideline. The Journal of Clinical Endocrinology \& Metabolism 96(7): 1911-1930.

3. Marya S Sabir, Mark R Haussler, Sanchita Mallick, Ichiro Kaneko, Daniel A Lucas, et al. (2018) Optimal vitamin D spurs serotonin: 1,25-dihydroxyvitamin D represses serotonin reuptake transport (SERT) and degradation (MAO-A) gene expression in cultured rat serotonergic neuronal cell lines Genes \& Nutrition 13: 19.

4. Saccone D, Asani F, Bornman L (2015) Regulation of the vitamin D receptor gene by environment, genetics and epigenetics. Gene 561(2): 171-180.

5. Zerwekh JE (2008) Blood biomarkers of vitamin D status. The American journal of clinical nutrition 87(4): 1087S-1091S.

6. Trang HM, Cole DE, Rubin LA, Pierratos A, Siu S, et al. (1998) Evidence that vitamin D3 increases serum 25-hydroxyvitamin D more efficiently than does vitamin D2. The American journal of clinical nutrition 68(4): 854-858.

7. Norman AW (2008) From vitamin D to hormone D: fundamentals of the vitamin D endocrine system essential for good health. The American journal of clinical nutrition 88(2): 491S-499S.

8. Bouillon R, Carmeliet G, Daci E, Segaert S, Verstuyf A (1998) Vitamin D metabolism and action. Osteoporosis international 8(8): S013-S019.

9. M Prince (2003) Qualiative Research. Practical Psychiatric Epidemiology Oxford University Press New York, pp. 377-384.

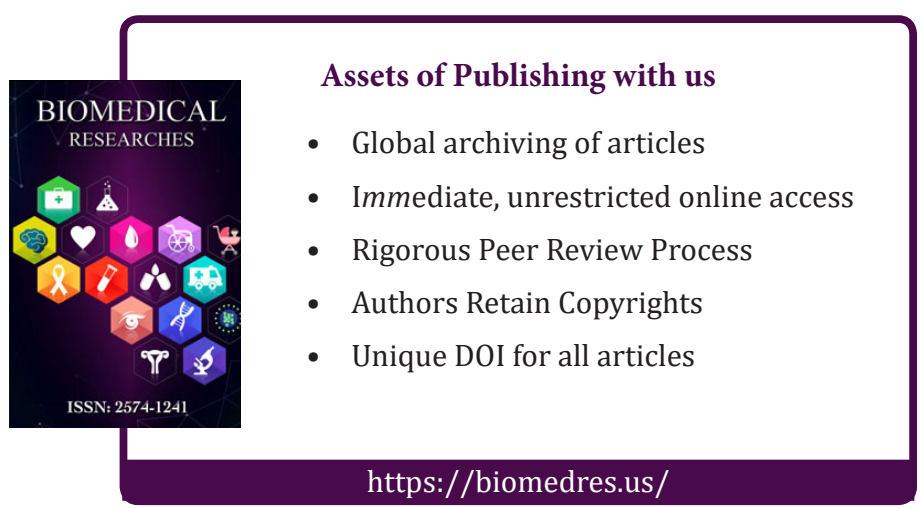

